\title{
Genetic variation in IL-17RA is functionally associated with chronic rejection after lung transplantation
}

D. Ruttens ${ }^{1 *}$, E. Wauters ${ }^{2,3 *}$, M. Kiciński ${ }^{4}$, S.E. Verleden ${ }^{1}$, E. Vandermeulen ${ }^{1}$, R. $\operatorname{Vos}^{1}$, D.E. Van Raemdonck ${ }^{1}$, T.S. Nawrot ${ }^{4,5}$, D.Lambrechts ${ }^{2,3}$, G.M. Verleden ${ }^{1}$, B.M. Vanaudenaerde ${ }^{1}$

${ }^{1}$ Lung Transplant Unit, Lab of Pneumology, KU Leuven, University Hospital Gasthuisberg

Leuven, Belgium; ${ }^{2}$ Vesalius Research Centrum, VIB, Leuven, Belgium; ${ }^{3}$ Laboratory for

Translational Genetics, KU Leuven, Leuven, Belgium; ${ }^{4}$ Centre for Environmental Sciences, Hasselt University, Diepenbeek, Belgium; ${ }^{5}$ Department of Public Health, KU Leuven

* These authors contributed equally to this work

Running title: Genetics and outcome after LTx

Key words: lung transplantation, genetics, IL-17, chronic rejection, neutrophils.

Address for correspondence: Bart Vanaudenaerde

Lab of Pneumology, Lung Transplantation Unit

KU Leuven

Herestraat 49, B-3000 Leuven, Belgium

Tel: + 3216330195 Fax: + 3216347124

E-mail: bart.vanaudenaerde@med.kuleuven.be 


\section{Abbreviations:}

AR: acute rejection

BAL: bronchoalveolair lavage

BOS: bronchiolitis obliterans syndrome

CAV-1: caveolin-1

CD14: cluster of differentiation 14

CF: cystic fibrosis

CI: confidence interval

CMV: cytomegalovirus,

COPD: chronic obstructive pulmonary disease

CRP: C-reactive protein

GERD: gastroesophageal reflux disease

HL: heart-lung transplantation

HR: hazard ratio

IFN- $\gamma$ : interferon gamma

IL-17RA: Interleukin-17 receptor A

IL-23R: Interleukin-23 receptor

KIRs: killer immunoglobulin-like receptors

LB: lymphocytic bronchiolitis

LTx: lung transplantation

MMP-7: matrix metalloproteinase-7

PGD: primary graft dysfunction.

SLTx: single lung transplantation

SSLTx: bilateral lung transplantation

TGF- $\beta 1$ : transforming growth factor beta-1

TLR: toll like receptors

TNF- $\alpha$ : tumor necrosis factor alfa

WBC: white blood cells 


\section{ABSTRACT}

Chronic rejection is the major cause of morbidity and mortality after lung transplantation. IL17 producing cells, inducers of airway neutrophilia, play a prominent role in chronic rejection. We investigated the association between genetic variants in the IL-17/IL-23 pathway and outcome after lung transplantation. Six genetic variants in IL-17 and IL-23 receptor genes were genotyped in 497 lung transplant patients. Associations with chronic rejection, mortality, airway and systemic inflammatory parameters were assessed. The rs879574A, genetic variant in the IL-17A receptor gene, was associated with chronic rejection. In particular, carriers of the rs879574 at-risk A-allele exhibited increased susceptibility to chronic rejection with multivariable-adjusted hazard ratio of $1.47(\mathrm{CI}=1.07-2.03$; $\mathrm{p}=0.004)$, but no association was found with mortality $(\mathrm{CI}=0.71-1.41 ; \mathrm{p}=0.14)$. Also the prevalence of acute rejection was higher in the at-risk population $(\mathrm{p}=0.001)$. Interestingly, rs879574A was associated with airway neutrophilia $(\mathrm{p}=0.020)$, suggesting that this variant may functionally affect the IL-17A receptor gene and thereby contribute to chronic rejection after lung transplantation. We conclude that rs879574A is associated with chronic rejection after lung transplantation, and is functionally associated with airway neutrophilia. Pre-transplant determination of this genetic variant may improve treatment and follow-up of our patients, aiming to reduce acute and chronic rejection. 


\section{INTRODUCTION}

Lung transplantation (LTx) is the ultimate treatment option for selected patients suffering from specific end-stage pulmonary disorders. However, after LTx, mortality rates remain relatively high, mainly due to the occurrence of chronic rejection (1). Chronic rejection, also defined as bronchiolitis obliterans syndrome (BOS) and characterized by an irreversible obstructive lung function, threatens over $50 \%$ of the lung transplant recipients within 5 years after LTx (2). Chronic rejection is accepted to be both an alloantigen dependent and independent process for which many risk factors have been identified, including acute rejection, lymphocytic bronchiolitis, the presence of auto-antibodies against collagen $\mathrm{V}$, colonization with micro-organisms and air pollution (3-5). These insults will activate the immune system and increase airway neutrophilia, which will lead to epithelial damage, excessive airway wall repair and finally fibrosis/obliteration of the airways $(1 ; 6)$. However, the underlying mechanisms of chronic rejection remain to be elucidated. It is suggested that IL-17 producing T-cells are key cells to induce a severe neutrophilic response linked to several chronic inflammatory conditions, including COPD, asthma and cystic fibrosis $(7 ; 8)$. The prominent role of IL-17 T-cells is confirmed in lung biopsies of patients suffering from these severe respiratory diseases (9-12). After LTx, IL-17 is involved in ischemic reperfusion injury (13), but also in acute (14) and chronic rejection (15).

Genetic predisposition may also play a role in chronic rejection after LTx. But, its role has not yet been thoroughly investigated, mainly due to smaller cohort sizes. Single center studies were unsuccessful to associate genetic variants in the genes encoding tumor necrosis factor alfa (TNF- $\alpha)$, interleukins (IL-6, IL-10), interferon gamma (IFN- $\gamma$ ) and transforming growth factor beta-1 (TGF- $\beta 1$ ) with the development of chronic rejection (16-20). On the other hand, some small cohort studies could associate chronic rejection with genetic variants 
in toll like receptors (TLR-2, TLR-4, TLR-9), CD14, caveolin-1 (CAV-1), killer immunoglobulin-like receptors (KIRs), and matrix metalloproteinase-7 (MMP-7) (19;21-27).

In the present study, we postulate that genetic variants in IL-17 receptor (IL-17R) and IL-23 receptor (IL-23R) genes may predispose lung transplant patients to increased risk for chronic rejection and possibly death. Therefore, we aimed to investigate the association between genetic variants in IL-17R and IL-23R genes with outcome after LTx in the Leuven Lung Transplant cohort. In particular, our specific aims were: $i$ ) to investigate the association between IL-17R and IL-23R genetic variants, chronic rejection and mortality after LTx and ii) to assess the correlation between the selected variants and airway neutrophilia. 


\section{METHODS}

\section{Study design}

This study included the entire Leuven lung transplant cohort that was recruited between April 1991 and December 2010. Patient's follow-up was recorded until August 2011, resulting in a minimal follow-up of at least 7 months. The study was approved by the Ethics Committee (S54739) of the Leuven University Hospitals, and all subjects consented prior to study participation. All patients received triple immunosuppression with cyclosporine or tacrolimus, azathioprine or mycophenolate mophetil, corticosteroids and an induction treatment of rabbit anti-thymocyte globulin (rATG). Chronic rejection was defined according to International Society for Heart and Lung Transplantation (ISHLT) criteria (2). Chronic rejection is defined as a persistent decline of FEV1 of at least $20 \%$ compared to the best postoperative value where no other explanation was found using CAT scan, bronchoscopy, transbronchial biopsies, bronchoalveolar lavage and cultures. Acute rejection (AR) and lymphocytic bronchiolitis (LB) were defined on histopathology according to the ISHLT guidelines (28). AR/LB was analyzed as a binary variable by contrasting at least one AR/LB event during follow-up versus being free of AR or LB. Also "severe" grades of AR ( $\geq A 2) / L B$ (>B2, according to the old histopathological criteria for LB) were analyzed separately. Acute rejection was treated with a 3 day course of high dose intravenous corticosteroids with subsequent oral tapering or an increased oral steroid boost. Chronic rejection was treated with an increase or shift in immunosuppression or oral tempered dose of steroids, azitromycin, total lymphoid irradiation and/or montelukast (29).

Patient's characteristics included gender, age, time of LTx, type of LTx (single lung transplantation (SLTx) versus bilateral lung transplantation (SSLTx) and heart-lung transplantation (HL)) and type of underlying lung disease. Clinical follow-up data included ischemic time, primary graft dysfunction (PGD) at 48 hours after LTx (30), the number of 
acute rejections, lymphocytic bronchiolitis, respiratory infections, CMV infections (29), CMV status (donor/recipient), gastroesophageal reflux disease (GERD, assessed either by $\mathrm{pH}$ impedance or gastroscopy within the first 2 years after transplantation) (29), bronchoalveolar lavage (BAL) cell profile, C-reactive protein (CRP, which is a marker for systemic inflammation), date of diagnosis of chronic rejection, start of azithromycin therapy and day of death. Infections were defined as respiratory events with need for antibiotics or hospitalization. Bronchoscopies with BAL (2x50ml of saline) and biopsy in combination with cell count/differentiation and histological evaluation were performed routinely at defined intervals $(90,180,360$ days) post-transplantation, as previously reported (31). The systemic collection of BAL in our centre was started in 2001. We included all patients for whom a BAL was available on at least one of the following postoperative days 90, 180, and 360. The number of subjects in all analysis is reported in Table 1: at day $90(\mathrm{n}=250 \mathrm{TT}, \mathrm{n}=80$ AA+AT), day $180(\mathrm{n}=228 \mathrm{TT}, \mathrm{n}=75 \mathrm{AA}+\mathrm{AT})$ and at day $360(\mathrm{n}=222 \mathrm{TT}, \mathrm{n}=69$ AA+AT). In total 266 patients of the TT-genotype (71\%) and 85 patients of the AA/AT genotype (69\%) had at least one BAL at the different time points. CxCL8 (IL-8) in BAL fluid was determined by ELISA, as previously described (4). Retransplantation $(n=23)$ was considered as a separate transplantation for outcome analyses, since a second allograft was evaluated in an already genotyped recipient, as previously described (5).

\section{Genotyping}

Recipient DNA was extracted from peripheral blood or, when unavailable, from explanted lung tissue. DNA from blood samples was extracted using the Qiagen QIAamp DNA Blood Midi kit according to the supplier's instructions (Qiagen, Hilden, Germany). For DNA extraction from lung tissue embedded in paraffin blocks, paraffin was removed by xylene, followed by two washes with ethanol. After the paraffin removal steps, tissue was digested 
with proteinase K solution and DNA was extracted by using Qiagen DNeasy Blood \& Tissue kit (according to the supplier's instructions). For the control of DNA purity, $1 \mu$ of genomic DNA was used to measure the $260 / 280$ and $260 / 230$ ratios by use of a Nanodrop-1000 (NanoDrop Technologies,Wilmington, DE). Only samples with a 260/280 ratio <2 and a 260/230 ratio <1 were accepted. DNA (5ng/ $\mu$ l) was aliquoted into 384-well plates and genotyped at the Vesalius Research Center (Leuven).

Genotyping for rs879574 (IL-17RA gene), rs2201841 (IL-23R gene), rs10489628 (IL23R gene), rs2066808 (IL-23A gene), rs1343151 (IL-23R gene) and rs1569922 (IL-23R gene) (32-37) was performed in a blinded manner using iPLEX technology on a MassARRAY Compact Analyser (Sequenom Inc., San Diego, CA, USA), as reported previously $(38 ; 39)$. Automated genotyping calls were generated using the MassARRAY RTTM software and were validated by manual review of the raw mass spectra. Quality control was performed by genotyping 12 samples in duplicate, with a duplicate concordance of $100 \%$.

\section{Statistical analysis}

Graph prism 4.0 software (San Diego, CA, USA) was used for statistical analysis of patient characteristics. Results are presented in numbers (percentage) or with the mean \pm SEM. Mann-Whitney test (non-parametric t-test), chi-square (contingency tables) and one-way ANOVA (Kruskal-Wallis) where used, where appropriate. A p-value $<0.05$ was considered significant.

For further database management and statistical analysis, we used SAS software, version 9.2 (SAS Institute Inc, Cary, NC). We performed survival analysis to study the effect of genotype on the hazard of chronic rejection (primary analysis). Patients for whom the endpoint was not observed before 1/8/2011 were treated as censored observations. In the analysis of chronic rejection, observations were also censored, when the patient died without evidence of chronic 
rejection. For each patient, the exact date of the endpoint or censoring was available. The survival analysis was performed for 6 genes. Therefore, we used the Bonferroni correction method in this analysis, which resulted in a significance threshold of $p<0.0083$. The $p$-values reported in the text are unadjusted. In our study, secondary analysis on the effect of genotypes on the hazard of mortality was performed. We contrasted survival curves by Kaplan-Meier survival function estimates and the log-rank test. We applied Cox regression to estimate the hazard ratio of chronic rejection and mortality associated with the genotypes for the selected genetic variants, while adjusting for age, gender, time of LTx, type of LTx, underlying lung disease and use of azithromycin. All these variables were a priori chosen.

A mixed model allowing for subject-specific intercepts and slopes was used to investigate the effect of the rs879574 genotypes (AA/AT versus TT) on $i$ ) the total number and percentage neutrophilia in BAL fluid, $i$ ) the total number and percentage of white blood cells (WBC) in BAL fluid, iii) concentration of CxCL8 (IL-8) in BAL fluid, and iv) serum CRP measured 90, 180, and 360 days after transplantation. All dependent variables were transformed logarithmically to normalize the distribution of the residuals. The covariates age, gender, time of LTx, type of LTx, type of underlying lung disease, and use of azithromycin were included in the model. 


\section{RESULTS}

\section{Study population}

In total, we included 568 patients. For 43 patients, DNA extraction failed and, consequently, no DNA was available for genotyping. The genotyping success rate for each of the 6 selected variants in the remaining 525 patients was higher than $90 \%$ (90\% to $96 \%$ ).

First, we assessed whether any of the selected genetic variants associated with our primary endpoint, i.e. chronic rejection. We could not find an association for any of the genetic variants in IL-23R genes. On the other hand, the IL-17RA genetic variant (rs879574A) did influence chronic rejection after LTx. The genotyping success rate for rs 879574 was $95 \%$.

\section{The rs879574A population characteristics}

Of the 497 successfully genotyped patients, 373 carried the TT genotype, 113 the AT genotype and 11 the AA genotype. Patient's characteristics according to AA/AT and TT genotypes are summarized in Table 1. There were no significant differences in gender $(\mathrm{p}=0.84)$, age $(\mathrm{p}=0.91)$, era of LTx (before 2001 versus after 2001) $(\mathrm{p}=0.99)$, type of LTx $(\mathrm{p}=0.58)$ and type of underlying lung disease $(\mathrm{p}=0.15)$ between both subgroups. Immunosuppressive treatment did not differ between the genotypes comparing azathioprine versus mycophenolate mophetil $(\mathrm{p}=0.85)$ and tacrolimus versus cyclosporine $(\mathrm{p}=0.69)$. Race/ethnicity between the both genotypes did not differ $(p=0.18)$ in our predominantly Caucasian population (in the AA/AT and TT genotype respectively $96 \%$ and $98 \%$ ). 


\section{The rs879574A variant correlates with chronic rejection after LTx}

As mentioned above, we identified a significant association between rs $879574 \mathrm{~A}$ and chronic rejection. In particular, the rs879574 A-allele was significantly more common in patients diagnosed with chronic rejection (18\% versus $11 \%$, respectively in the group with and without chronic rejection, $\mathrm{p}=0.002$ ), suggesting that the A-allele is the at-risk allele for rs 879574. These findings are consistent with a recent paper identifying an increased risk of Crohn's disease in patients carrying the rs879574 A-allele (37). The frequency of the A-allele was $14 \%$ in our study population, which is comparable to the frequency in the general European population (40).

At the genotypic level, the estimated risk of subjects carrying one risk allele (A-allele) was significantly higher than the risk of those carrying no A-allele, but was comparable to the risk of homozygous A-allele carriers (hazard ratio (HR) of 1.63 and 1.86, respectively for the AA and AT genotype). These results indicate a dominant effect of the risk allele and, therefore, we analyzed the association of rs879574A with outcome after LTx using a dominant model (i.e. AA/AT versus the TT genotype). In univariate analysis, rs879574A significantly associated with an increased risk of chronic rejection ( $\mathrm{p}=0.0034$ according to a dominant risk model, figure1A). When adjusting for age, gender, date of transplantation, LTx type, diagnosis and use of azithromycin, we identified an almost 50\% higher risk of chronic rejection for the AA/AT genotype compared to the TT genotype (HR=1.47, 95\% CI: [1.072.03], $\mathrm{p}=0.004)$ (Table 2). Multi-variate analysis excluding retransplantations $(\mathrm{n}=23$, TT genotype $n=17$ and AT/TT genotype $n=6$ ) showed comparable results. 


\section{The rs879574A variant does not correlate with mortality after LTx}

Unadjusted no significant difference was identified in mortality rates between rs879574 genotypes ( $\mathrm{p}=0.24$, figure 1B). The mortality curves were similar the first 3 years after transplantation, but seemed to diverge in favor of carriers of the TT-genotype afterwards. Our exploratory (unadjusted) analysis excluding the first three years after transplantation suggested a higher mortality in the AT/TT-subgroup ( $\mathrm{p}=0.049)$ (figure 1C). The adjusted model confirmed the comparable mortality rates between $\mathrm{rs} 879574$ genotypes $(\mathrm{p}=0.16$, table 2)

In the overall cohort, there was no significant relationship between the use of azithromycin and the development of chronic rejection $(\mathrm{p}=0.18)$, or the posttransplant survival $(\mathrm{p}=0.30)$. An important observation was that a higher proportion of patients were using azithromycin therapy in the AA+AT group compared to the TT group ( $\mathrm{p}=0.047$; Table $1)$.

\section{Associations between rs879574A and risk factors}

Acute rejection, one of the most important risk factors for chronic rejection, was more frequently observed after adjustment for confounders in the AA/AT-subgroup ( $\mathrm{p}=0.001)$. On the other hand, we did not observe a significant difference between rs879574 genotypes and the presence of GERD ( $\mathrm{p}=0.66)$, lymphocytic bronchiolitis (LB) ( $\mathrm{p}=0.38$ ), respiratory (bacterial and fungal) infections $(\mathrm{p}=0.20)$ and CMV infection $(\mathrm{p}=0.41)$ (table 1). In addition, there was also no difference in acute rejection grades $(A \geq 2)(p=0.40)$, or $\operatorname{LB}(B>2)(p=0.17)$. Pretransplant donor-receptor status of $\operatorname{CMV~}(\mathrm{p}=0.81)$, ischemic time $(\mathrm{p}=0.42)$ and grade of primary graft dysfunction $(\mathrm{p}=0.61)$ did not differ between the genotypes. 


\section{The rs879574A variant correlates with BAL neutrophilia.}

To confirm the potential functional relevance of rs879575A for LTx outcome, we assessed the association with BAL neutrophilia, BAL CxCL8 levels and serum CRP (measured at 90, 180, and 360 days after transplantation), while adjusting for age, gender, type of LTx, type of underlying disease, time of LTx and the use of azitromycin (Figure 2). In the AA/AT subgroup, percentage BAL neutrophilia was 1.59 times higher compared with the group of TT carriers (CI: [1.07-2.36], p=0.023). Likewise, total neutrophilia was 1.68 times higher for AA/AT subgroup than in the TT group (CI: [1.09-2.61], $\mathrm{p}=0.020$ ). The effect on absolute number of BAL lymphocytes did not reach prespecified p-value (estimate: 1.30, CI: [0.97-1.74], $\mathrm{p}=0.082$ ). Percentage of BAL lymphocytes did not differ significantly between both subgroups. Total white blood cell count in the BAL was 1.34 times higher in carriers of the AA and AT genotype (CI: [1.08-1.65], p=0.007). CxCL8 levels in BAL were comparable between both subgroups (estimate: 1.13, CI: [0.78-1.62], $\mathrm{p}=0.52$ ). The systemic inflammation was evaluated by analyzing plasma CRP and tended to be higher in AA and AT carriers (estimate: 1.31, CI: [0.98-1.75], $\mathrm{p}=0.072)$ (tabel2). 


\section{DISCUSSION}

Our study is the first to identify a role of a genetic variant (rs879574) in the IL-17RA gene in chronic rejection after LTx (located in the IL-17RA of chromosome 22). Patients carrying the at-risk A-allele had a $47 \%$ increased risk of developing chronic rejection in comparison with carriers of the TT genotype $(\mathrm{p}=0.004)$. The A-allele also increased the risk of ever experiencing acute rejection $(\mathrm{p}=0.001)$, but did not influence the presence of lymphocytic bronchiolitis or respiratory infections after LTx ( $\mathrm{p}=0.38$ and $\mathrm{p}=0.22$, respectively). Interestingly, rs879574 was associated with total airway neutrophilia $(\mathrm{p}=0.020)$, suggesting that this variant may functionally affect the IL-17RA gene and thereby contribute to chronic rejection after LTx.

Recently, IL-17 producing T-cells have been associated with chronic rejection, as a driving factor of (airway) neutrophilia. Besides environmental and autoimmune differentiation/activation, we now demonstrated a genetic predisposition to chronic rejection via genetic variation in the IL-17RA gene. The IL-17 receptor is present on most cells within the lung, including immune cells and structural cells, and is specifically activated by IL-17, which may lead to an increased (airway) neutrophilia, via CxCL8 and other interleukin release (41).

We believe that our findings are further strengthened by the demonstration of a functional consequence of the investigated IL-17RA genetic variant, as there is a link with increased airway neutrophilia at day 90, 180 and 360 after LTx, thus at time points preceding the diagnosis of chronic rejection. These findings are important, as persistent BAL neutrophilia is an established risk factor for chronic rejection (42). Total leukocyte count was associated with this genetic variant and trends were present for BAL lymphocytosis as well as serum CRP, which all are known to be involved in the development of chronic rejection. 
Unfortunately, we were not able to demonstrate a link between rs879574A and CxCL8. This may be due to the large variation in measurements and larger range in BAL concentrations. Moreover, there are many more inducers of neutrophilia than CxCL8. Since acute rejection remains the most important risk factor for chronic rejection and it may be accompanied by increased IL-17 and neutrophilia in BAL samples (26), it is not surprising that the AA+AT group demonstrates more acute rejections.

For the present study, we included 497 patients, making this one of the largest cohorts used for a genetic study in the field of LTx. The single center approach may result in a more standardized and uniform care, which reduces possible bias by therapy. We are well aware that the lack of a replication cohort is a major concern, but finding a similar cohort of this size and with matched patient data was unfortunately not possible. On the other hand, we did demonstrate that this genetic variant in the IL-17RA gene had a functional effect on an accepted mechanistical element of chronic rejection after lung transplantation, being airway neutrophilia. However IL-17 protein levels in BAL is largely impossible to measure, based on previous experimental work done in our lab (41). Therefore, we determined BAL neutrophilia and chronic rejection as a surrogate marker for IL-17, although we are aware that IL-17 is not the only inducer of BAL neutrophilia.

Unexpectedly, we could not demonstrate a link between rs879574A and mortality after LTx. A possible explanation might be the use of azithromycin therapy, which is an accepted and effective treatment for chronic rejection and airway neutrophilia. Within our cohort, most of the patients (70\%) only received azithromycin after diagnosis of chronic rejection (BOS), whereas only a small fraction $( \pm 10 \%)$ received it in a preventive manner. Previous studies demonstrated that overall mortality is reduced when receiving azithromycin (29). This may help to explain why we did not observe an association between rs879459A and crude mortality. Nevertheless, the link between the genetic variant in the IL17RA gene and airway 
neutrophilia is reflected by a higher use of azithromycin in the subgroup carrying the AA or AT genotype $(\mathrm{p}=0.047)$ based on clinical indications. Therefore, azithromycin therapy was considered as a confounding factor in all analyses, however, an effect on the development of BOS $(\mathrm{p}=0.14)$ and mortality $(\mathrm{p}=0.30)$ could not be demonstrated. Hence, azithromycin does probably play a role in the association between the IL-17RA genetic variant and chronic rejection, but due to its widespread but unstandardized use during the last decade, we could not find a statistical difference. We are well aware that azithromycin usage is a poor endpoint to a genetic risk, although it can give an idea over the functionality of our polymorphism. The lack of an association between rs879574A and crude mortality could also be explained by the fact that chronic rejection needs time to develop and may only influence survival several years after diagnosis (43). This may explain the curve divergence after 3 years. Censoring for the first 3 years after LTx indeed showed a better survival in favor of the carriers of the TTgenotype.

Our findings are unique in the lung transplant field and need to be confirmed, but, if valid, may open several perspectives. They can be relevant for other chronic inflammatory pulmonary diseases such as COPD, CF and asthma, which are also IL-17/neutrophil related, and possibly also for other types of solid organ transplantation (8-11). In the clinical practice in our center, a systematic follow-up program with BAL is performed. When high BAL neutrophilia is detected, azithromycin is started as initial treatment when there is no indication for an infection. On the other hand, in some centers where no routine follow-up BAL is available, it can be useful to determine rs879547A prior to LTx to stimulate follow-up, given the known link between airway neutrophilia and chronic rejection. As mentioned before, untreated neutrophilia may indeed lead to chronic rejection (42). Early azithromycin treatment of patients with the at-risk A-allele for 879459 could therefore have an impact on the prevalence of chronic rejection. 
In conclusion, we demonstrated that a genetic variant in the IL-17RA gene is associated with increased airway neutrophilia and the development of acute and chronic rejection. Determination of this genetic variant prior to LTx may change our point of view in the treatment and standard care follow-up of our patients by giving the 'risk' group azithromycin early on to prevent the development of chronic rejection. This, however, needs further prospective investigation. 


\section{Acknowledgments}

Funding: Glaxo Smith Kline (Belgium) chair in respiratory pharmacology at the KU Leuven; grants from the Research Foundation Flanders (FWO): G.0723.10, G.0753.10, G.0679.12 and G.0705.12; grant from the KU Leuven: OT10/050. EW and MK are junior and BMV and DEVR are senior research fellows of the FWO.

The authors of this manuscript have no conflicts of interest to disclose as described by the journal of heart and lung transplantation. 


\section{FIGURE LEGENDS}

Figure 1: Freedom from chronic rejection (A) and mortality (B/C) according to $\mathbf{r s 8 7 9 5 7 4}$ genotypes (AA/AT versus TT). A) Unadjusted Kaplan-Meier curves in patients after LTx classified according to genotype: TT $(n=124)$ versus AT and AA $(n=373)$. AA+AT genotype has a significant higher risk for the development of chronic rejection $(\mathrm{p}=0.003)$

B) Unadjusted Kaplan-Meier survival curves in patients after LTx classified according to genotype: TT $(n=124)$ versus AT and AA ( $n=373)$. AA+AT genotype has no significant higher risk for mortality $(\mathrm{p}=0.24)$

C) Unadjusted Kaplan-Meier survival curves in patients censored for the first 3 years after LTx classified according to genotype: AA+AT genotype implicates significant higher risk for mortality $(\mathrm{p}=0.049)$. With our current treatment for chronic rejection or BOS we only see an effect a few years after LTx. So this graph is shown, to see the long term effect of chronic rejection on mortality of this polymorphism.

Figure 2: Association between the IL-17R polymorphism and different blood or BAL cellular characteristics. The effects are expressed as a multiplicative change of blood or cellular characteristics associated with the A-allele (AA and AT) compared with TT-genotype. The dotted line indicates no change in concentration or percentage. Red parameter estimates demonstrate a significant association, black a non-significant association. $\mathrm{BAL}=$ broncho-alveolair lavage, $\mathrm{WBC}=$ white blood cell count, $\mathrm{CRP}=\mathrm{C}$-reactive protein. 
Reference List

(1) Verleden GM. Chronic allograft rejection (obliterative bronchiolitis). Semin Respir Crit Care Med 2001 Oct;22(5):551-8.

(2) Estenne M, Maurer JR, Boehler A, Egan JJ, Frost A, Hertz M, et al. Bronchiolitis obliterans syndrome 2001: an update of the diagnostic criteria. J Heart Lung Transplant 2002 Mar;21(3):297-310.

(3) Burlingham WJ, Love RB, Jankowska-Gan E, Haynes LD, Xu Q, Bobadilla JL. IL-17-dependent cellular immunity to collagen type $\mathrm{V}$ predisposes to obliterative bronchiolitis in human lung transplants. J Clin Invest 2007 Nov;117(11):3498-506.

(4) Vanaudenaerde BM, Dupont LJ, Wuyts WA, Verbeken EK, Meyts I, Bullens DM, et al. The role of interleukin-17 during acute rejection after lung transplantation. Eur Respir J 2006 Apr;27(4):779-87.

(5) Nawrot TS, Vos R, Jacobs L, Verleden SE, Wauters S, Mertens V, et al. The impact of traffic air pollution on bronchiolitis obliterans syndrome and mortality after lung transplantation. Thorax 2011 Sep;66(9):748-54.

(6) Boehler A, Estenne M. Obliterative bronchiolitis after lung transplantation. Curr Opin Pulm Med 2000 Mar;6(2):133-9.

(7) Kolls JK, Khader SA. The role of Th17 cytokines in primary mucosal immunity. Cytokine Growth Factor Rev 2010 Dec;21(6):443-8.

(8) O'Shea JJ, Steward-Tharp SM, Laurence A, Watford WT, Wei L, Adamson AS, et al. Signal transduction and Th17 cell differentiation. Microbes Infect 2009 Apr;11(5):599-611.

(9) Alcorn JF, Crowe CR, Kolls JK. TH17 cells in asthma and COPD. Annu Rev Physiol 2010;72:495516.

(10) Bullens DM, Truyen E, Coteur L, Dilissen E, Hellings PW, Dupont LJ, et al. IL-17 mRNA in sputum of asthmatic patients: linking T cell driven inflammation and granulocytic influx? Respir Res 2006;7:135.

(11) Dubin PJ, McAllister F, Kolls JK. Is cystic fibrosis a TH17 disease? Inflamm Res 2007 Jun;56(6):221-7.

(12) Pene J, Chevalier S, Preisser L, Venereau E, Guilleux MH, Ghannam S, et al. Chronically inflamed human tissues are infiltrated by highly differentiated Th17 lymphocytes. J Immunol 2008 Jun 1;180(11):7423-30.

(13) Shilling RA, Wilkes DS. Role of Th17 cells and IL-17 in lung transplant rejection. Semin Immunopathol 2011 Mar;33(2):129-34. 
(14) Vanaudenaerde BM, Meyts I, Vos R, Geudens N, De WW, Verbeken EK, et al. A dichotomy in bronchiolitis obliterans syndrome after lung transplantation revealed by azithromycin therapy. Eur Respir J 2008 Oct;32(4):832-43.

(15) Park H, Li Z, Yang XO, Chang SH, Nurieva R, Wang YH, et al. A distinct lineage of CD4 T cells regulates tissue inflammation by producing interleukin 17. Nat Immunol 2005 Nov;6(11):1133-41.

(16) Awad M, Pravica V, Perrey C, El GA, Yonan N, Sinnott PJ, et al. CA repeat allele polymorphism in the first intron of the human interferon-gamma gene is associated with lung allograft fibrosis. Hum Immunol 1999 Apr;60(4):343-6.

(17) Jackson A, Palmer S, Davis RD, Pappendick A, Pearson E, Savik K, et al. Cytokine genotypes in kidney, heart, and lung recipients: consequences for acute and chronic rejection. Transplant Proc 2001 Feb;33(1-2):489-90.

(18) Lu KC, Jaramillo A, Lecha RL, Schuessler RB, Aloush A, Trulock EP, et al. Interleukin-6 and interferon-gamma gene polymorphisms in the development of bronchiolitis obliterans syndrome after lung transplantation. Transplantation 2002 Nov 15;74(9):1297-302.

(19) Snyder LD, Hartwig MG, Ganous T, Davis RD, Herczyk WF, Reinsmoen NL, et al. Cytokine gene polymorphisms are not associated with bronchiolitis obliterans syndrome or survival after lung transplant. J Heart Lung Transplant 2006 Nov;25(11):1330-5.

(20) Vamvakopoulos JE, Taylor CJ, Green C, McNeil K, Wallwork J, Goodman R, et al. Interleukin 1 and chronic rejection: possible genetic links in human heart allografts. Am J Transplant 2002 Jan;2(1):76-83.

(21) Goldstein DR, Palmer SM. Role of Toll-like receptor-driven innate immunity in thoracic organ transplantation. J Heart Lung Transplant 2005 Nov;24(11):1721-9.

(22) Kastelijn EA, van Moorsel CH, Kazemier KM, Roothaan SM, Ruven HJ, Kwakkel-van Erp JM, et al. A genetic polymorphism in the CAV1 gene associates with the development of bronchiolitis obliterans syndrome after lung transplantation. Fibrogenesis Tissue Repair 2011;4:24.

(23) Palmer SM, Burch LH, Mir S, Smith SR, Kuo PC, Herczyk WF, et al. Donor polymorphisms in Toll-like receptor- 4 influence the development of rejection after renal transplantation. Clin Transplant 2006 Jan;20(1):30-6.

(24) Kastelijn EA, van Moorsel CH, Rijkers GT, Ruven HJ, Karthaus V, Kwakkel-van Erp JM, et al. Polymorphisms in innate immunity genes associated with development of bronchiolitis obliterans after lung transplantation. J Heart Lung Transplant 2010 Jun;29(6):665-71.

(25) Kastelijn EA, van Moorsel CH, Ruven HJ, Karthaus V, Kwakkel-van Erp JM, van de Graaf EA, et al. Genetic polymorphisms in MMP7 and reduced serum levels associate with the development of bronchiolitis obliterans syndrome after lung transplantation. J Heart Lung Transplant 2010 Jun;29(6):680-6.

(26) Kwakkel-van Erp JM, van de Graaf EA, Paantjens AW, van Ginkel WG, Schellekens J, van Kessel DA, et al. The killer immunoglobulin-like receptor (KIR) group A haplotype is associated with bronchiolitis obliterans syndrome after lung transplantation. J Heart Lung Transplant 2008 Sep;27(9):995-1001. 
(27) Palmer SM, Klimecki W, Yu L, Reinsmoen NL, Snyder LD, Ganous TM, et al. Genetic regulation of rejection and survival following human lung transplantation by the innate immune receptor CD14. Am J Transplant 2007 Mar;7(3):693-9.

(28) Stewart S, Fishbein MC, Snell GI, Berry GJ, Boehler A, Burke MM, et al. Revision of the 1996 working formulation for the standardization of nomenclature in the diagnosis of lung rejection. J Heart Lung Transplant 2007 Dec;26(12):1229-42.

(29) Vos R, Vanaudenaerde BM, Ottevaere A, Verleden SE, De Vleeschauwer SI, WillemsWidyastuti $A$, et al. Long-term azithromycin therapy for bronchiolitis obliterans syndrome: divide and conquer? J Heart Lung Transplant 2010 Dec;29(12):1358-68.

(30) Wauters S, Verleden GM, Belmans A, Coosemans W, De LP, Nafteux P, et al. Donor cause of brain death and related time intervals: does it affect outcome after lung transplantation? Eur J Cardiothorac Surg 2011 Apr;39(4):e68-e76.

(31) Vos R, Vanaudenaerde BM, De Vleeschauwer SI, Willems-Widyastuti A, Dupont $L$, Van Raemdonck DE, et al. C-reactive protein in bronchoalveolar lavage fluid is associated with markers of airway inflammation after lung transplantation. Transplant Proc 2009 Oct;41(8):3409-13.

(32) Bowes J, Orozco G, Flynn E, Ho P, Brier R, Marzo-Ortega H, et al. Confirmation of TNIP1 and IL23A as susceptibility loci for psoriatic arthritis. Ann Rheum Dis 2011 Sep;70(9):1641-4.

(33) Kim TH, Hong JM, Oh B, Cho YS, Lee JY, Kim HL, et al. Association of polymorphisms in the Interleukin 23 receptor gene with osteonecrosis of femoral head in Korean population. Exp Mol Med 2008 Aug 31;40(4):418-26.

(34) Lee YH, Choi SJ, Ji JD, Song GG. Associations between interleukin-23R polymorphisms and ankylosing spondylitis susceptibility: a meta-analysis. Inflamm Res 2012 Feb;61(2):143-9.

(35) Safrany E, Szell M, Csongei V, Jaromi L, Sipeky C, Szabo T, et al. Polymorphisms of the IL23R gene are associated with psoriasis but not with immunoglobulin A nephropathy in a Hungarian population. Inflammation 2011 Dec;34(6):603-8.

(36) Taylor KD, Targan SR, Mei L, Ippoliti AF, McGovern D, Mengesha E, et al. IL23R haplotypes provide a large population attributable risk for Crohn's disease. Inflamm Bowel Dis 2008 Sep;14(9):1185-91.

(37) McGovern DP, Rotter JI, Mei L, Haritunians T, Landers C, Derkowski C, et al. Genetic epistasis of IL23/IL17 pathway genes in Crohn's disease. Inflamm Bowel Dis 2009 Jun;15(6):883-9.

(38) Wauters E, Smeets D, Coolen J, Verschakelen J, De Leyn P, Decramer M, et al. The TERTCLPTM1L locus for lung cancer predisposes to bronchial obstruction and emphysema. Eur Respir J 2011 Oct;38(4):924-31.

(39) Lambrechts D, Buysschaert I, Zanen P, Coolen J, Lays N, Cuppens H, et al. The 15q24/25 susceptibility variant for lung cancer and chronic obstructive pulmonary disease is associated with emphysema. Am J Respir Crit Care Med 2010 Mar 1;181(5):486-93.

(40) A map of human genome variation from population-scale sequencing. Nature 2010 Oct 28;467(7319):1061-73. 
(41) Vanaudenaerde BM, De Vleeschauwer SI, Vos R, Meyts I, Bullens DM, Reynders V, et al. The role of the IL23/IL17 axis in bronchiolitis obliterans syndrome after lung transplantation. Am J Transplant 2008 Sep;8(9):1911-20.

(42) Vos R, Vanaudenaerde BM, De Vleeschauwer SI, Willems-Widyastuti A, Scheers H, Van Raemdonck DE, et al. Circulating and intrapulmonary C-reactive protein: a predictor of bronchiolitis obliterans syndrome and pulmonary allograft outcome. J Heart Lung Transplant 2009 Aug;28(8):799-807.

(43) Verleden GM, Vos R, De Vleeschauwer SI, Willems-Widyastuti A, Verleden SE, Dupont LJ, et al. Obliterative bronchiolitis following lung transplantation: from old to new concepts? Transpl Int 2009 Aug;22(8):771-9. 


\begin{tabular}{|c|c|c|c|}
\hline IL-17R polymorphism & AA/ AT & TT & P-value \\
\hline Number of patients & 124 & 373 & \\
\hline Female sex & $57(46 \%)$ & $177(47 \%)$ & 0.84 \\
\hline Age at LTx (years) & $47.5( \pm 1.2)$ & $47.6( \pm 0.6)$ & 0.91 \\
\hline Indication for LTx (n) & & & 0.15 \\
\hline Emphysema, $\alpha-1 \mathrm{ATD}$ & $49(40 \%)$ & $179(48 \%)$ & 0.16 \\
\hline Pulmonary fibrosis & $25(20 \%)$ & $51(14 \%)$ & 0.09 \\
\hline $\mathrm{CF} /$ Bronchiectasis & $19(15 \%)$ & $64(17 \%)$ & 0.64 \\
\hline Eisenmenger/PAHT & $13(11 \%)$ & $44(11 \%)$ & 0.69 \\
\hline Retransplant/Others & $18(14 \%)$ & $35(10 \%)$ & 0.11 \\
\hline $\begin{array}{l}\text { Transplantion time (transplanted after } \\
\text { 2001) }\end{array}$ & $95(77 \%)$ & $286(77 \%)$ & 0.99 \\
\hline Type LTx(SS/HL compared with S) & $91(73 \%)$ & $283(76 \%)$ & 0.58 \\
\hline AZI treatment & $65(53 \%)$ & $156(42 \%)$ & $0.04 *$ \\
\hline $\begin{array}{l}\text { Treatment } \\
\text { Azathioprine-mycophenolatemophetil } \\
\text { tacrolimus-cyclosporine }\end{array}$ & $\begin{array}{l}80(65 \%)-20(16 \%) \\
83(67 \%)-32(26 \%)\end{array}$ & $\begin{array}{l}252(68 \%)-51(14 \%) \\
241(65 \%)-105(28 \%)\end{array}$ & $\begin{array}{l}0.85 \\
0.69\end{array}$ \\
\hline \multicolumn{4}{|l|}{ Acute rejection history } \\
\hline $\begin{array}{l}\text { Any acute rejection (AR) } \\
\text { Severe } \mathrm{AR}(\geq \mathrm{A} 2)\end{array}$ & $\begin{array}{l}71(57 \%) \\
23(18 \%)\end{array}$ & $\begin{array}{l}146(39 \%) \\
63(17 \%)\end{array}$ & $\begin{array}{l}0.001^{*} \\
0.40\end{array}$ \\
\hline $\begin{array}{l}\text { Any lymphocytic bronchiolitis (LB) } \\
\text { Severe LB ( } \geq \text { B2) }\end{array}$ & $\begin{array}{l}40(32 \%) \\
21(17 \%)\end{array}$ & $\begin{array}{l}103(28 \%) \\
50(13 \%)\end{array}$ & $\begin{array}{l}0.38 \\
0.17\end{array}$ \\
\hline Chronic rejection & $60(48 \%)$ & $126(34 \%)$ & $0.003^{*}$ \\
\hline Time to chronic rejection (days) & 1097(105) & $1183(54)$ & 0.17 \\
\hline Death & $48(38 \%)$ & $121(32 \%)$ & 0.24 \\
\hline Time to death (days) & $1161(168)$ & $825(84)$ & 0.13 \\
\hline Respiratory infections & $50(40 \%)$ & $126(34 \%)$ & 0.19 \\
\hline GERD & $49(40 \%)$ & $143(38 \%)$ & 0.66 \\
\hline CMV infection & $7(6 \%)$ & $30(8 \%)$ & 0.41 \\
\hline $\begin{array}{l}\text { CMV status } \\
\text { D+/R+ } \\
\text { D+/R- } \\
\text { D-/R+ } \\
\text { D-/R- } \\
\text { Unknown } \\
\end{array}$ & $\begin{array}{l}23(18 \%) \\
20(16 \%) \\
28(23 \%) \\
38(30 \%) \\
15(13 \%)\end{array}$ & $\begin{array}{l}64(17 \%) \\
77(21 \%) \\
80(21 \%) \\
102(28 \%) \\
50(13 \%) \\
\end{array}$ & $\begin{array}{l}0.81 \\
0.72 \\
0.27 \\
0.79 \\
0.45 \\
0.71 \\
\end{array}$ \\
\hline Time Ischemia(min) & $312(99)$ & $319(101)$ & 0.42 \\
\hline $\begin{array}{l}\text { Grade I } \\
\text { Grade II } \\
\text { Grade III } \\
\text { Unknown }\end{array}$ & $\begin{array}{l}51(41 \%) \\
30(24 \%) \\
13(10 \%) \\
30(25 \%)\end{array}$ & $\begin{array}{l}151(40 \%) \\
89(24 \%) \\
46(12 \%) \\
87(24 \%)\end{array}$ & $\begin{array}{l}0.61 \\
0.90 \\
0.92 \\
0.43 \\
0.84 \\
\end{array}$ \\
\hline
\end{tabular}

Table 1: Characteristics of the cohort, subdivided according to rs879574 genotypes. Analysis is preformed with a t-test or a chi-square. Results are shown in numbers (percentage) or with the MEAN \pm SEM. A p-value $<0.05$ was considered significant. LTx=lung transplantation; SS= double sided LTx, S=single sided LTx; HL=heart-lung transplantation; $\alpha-1 \mathrm{ATD}=$ alpha-1-antitrypsin deficiency; $\mathrm{CF}=$ cystic fibrosis; $\mathrm{PAHT}=$ pulmonary arterial hypertension; $\mathrm{AZI}=$ azithromycin, $\mathrm{AR}=$ acute rejection, $\mathrm{LB}=$ lymphocytic bronchiolitis, $\mathrm{GERD}=$ Gastroesophageal reflux disease, $\mathrm{CMV}=$ cytomegalovirus, $\mathrm{PGD}=$ primary graft dysfunction. 


\begin{tabular}{|lccl|}
\hline IL-17R polymorphism & HR & $95 \%$ CI & P-value \\
\hline Mortality & 1.00 & {$[0.708-1.411]$} & 0.14 \\
Chronic rejection & 1.47 & {$[1.069-2.028]$} & 0.004 \\
\hline BAL & Estimate & $95 \%$ CI & P-value \\
\% Neutrophils & 1.59 & {$[1.066-2.356]$} & 0.023 \\
Total neutrophils & 1.68 & {$[1.088-2.608]$} & 0.020 \\
\% Lymphocytes & 0.90 & {$[0.683-1.193]$} & 0.471 \\
Total lymphocytes & 1.30 & {$[0.967-1.740]$} & 0.082 \\
Total WBC & 1.34 & {$[1.082-1.645]$} & 0.007 \\
IL-8/CxCL8 & 1.13 & {$[0.783-1.624]$} & 0.518 \\
Blood & Estimate & $95 \%$ CI & P-value \\
CRP & 1.31 & {$[0.976-1.750]$} & 0.072 \\
\hline
\end{tabular}

Table 2: Multivariate-analysis of chronic rejection and mortality for the rs879574 genotypes (AA/AT versus TT) (upper part). Using a proportional hazards Cox model with corrections for age, gender, LTx type, diagnosis, time of transplantation and the use of azithromycin. Hazard ratio (HR) and 95\% confidence interval are used. Estimates of lung and systemic inflammation in association with Il-17R polymorphisms (lower part). We applied Cox regression to estimate the hazard ratio of chronic rejection and mortality associated with the genotypes for the selected genetic variants, while adjusting for age, gender, time of LTx, type of LTx, underlying lung disease and use of azithromycin. A p-value $<0.05$ was considered significant. $\mathrm{WBC}=$ white blood cells, $\mathrm{HR}=$ hazard ratio, $\mathrm{CRP}=\mathrm{C}$-reactive protein 
Figure 1:

$$
\text { A }
$$

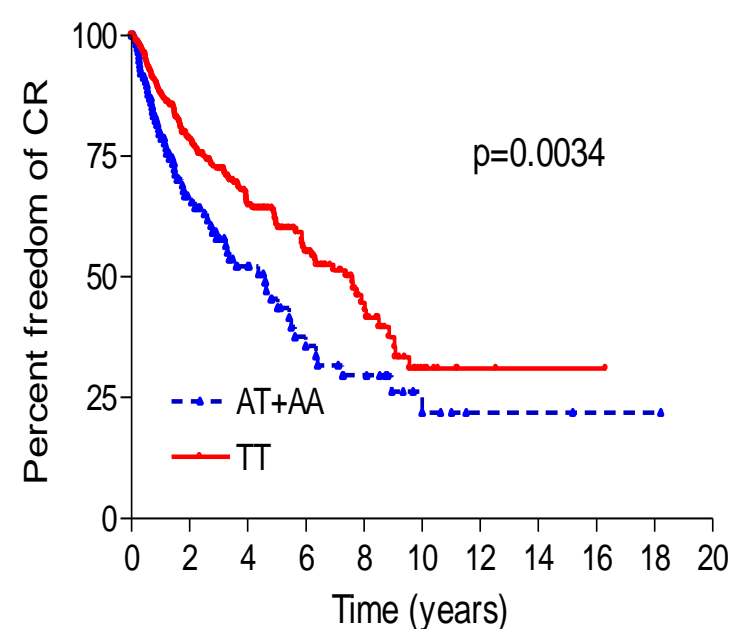

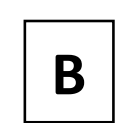

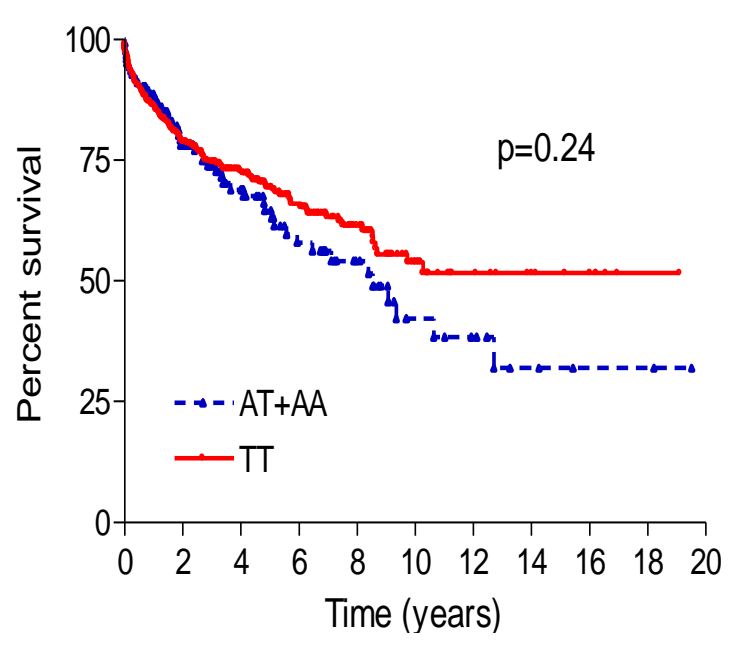

\section{c}

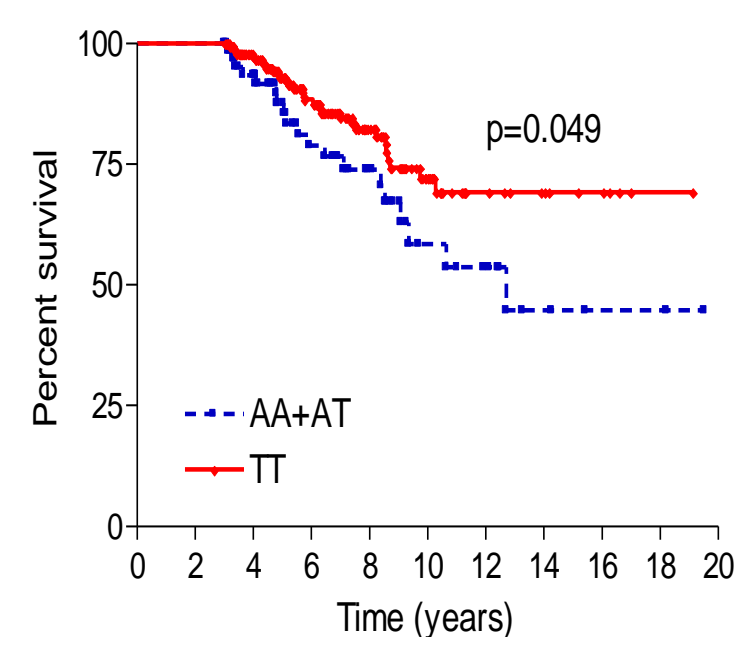


Figure 2

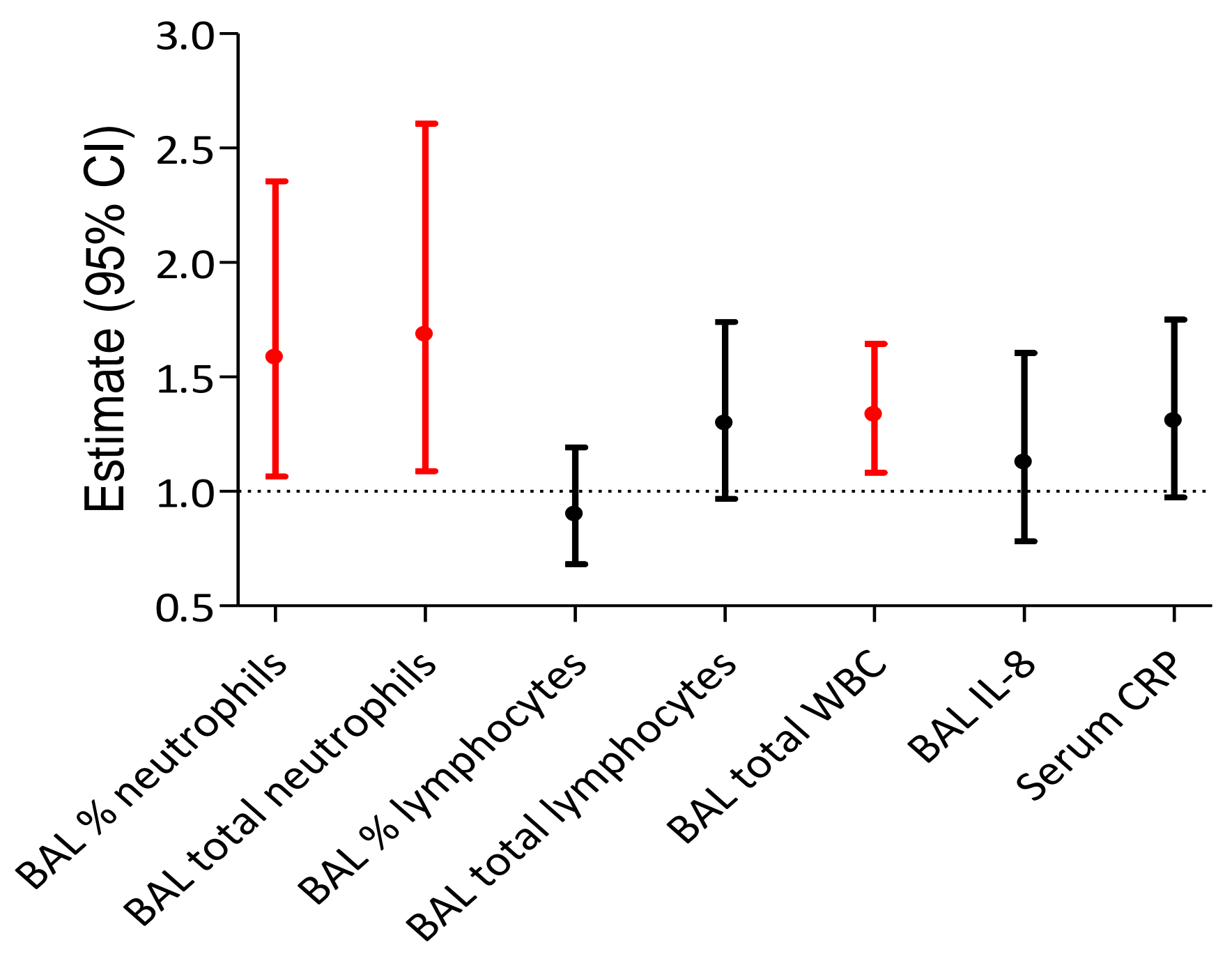

